\title{
Impact of type 1 diabetes on maternal long-term risk of hospitalisation and mortality: a nationwide combined clinical and register-based cohort study (The EPICOM study)
}

\author{
Sine Knorr ${ }^{1,2}$ (D) Svend Juul ${ }^{3}$ - Birgitte Bytoft ${ }^{4,5} \cdot$ Zuzana Lohse $^{6}$ - Tine D. Clausen ${ }^{7}$ - Rikke B. Jensen ${ }^{5,8}$. \\ Peter Damm ${ }^{4,5}$ • Henning Beck-Nielsen ${ }^{6}$. Elisabeth R. Mathiesen ${ }^{5,9}$ • Dorte M. Jensen ${ }^{6}$. Claus H. Gravholt ${ }^{1,2}$
}

Received: 1 November 2017 / Accepted: 24 January 2018 / Published online: 24 February 2018

(C) Springer-Verlag GmbH Germany, part of Springer Nature 2018

\begin{abstract}
Aims/hypothesis The aims of this study were to examine long-term mortality and morbidity rates in mothers with type 1 diabetes, both overall and according to the level of albuminuria prior to pregnancy, the presence of hypertension, pre-eclampsia and periconceptional $\mathrm{HbA}_{1 \mathrm{c}}$.

Methods This study was a part of the EPICOM (Environmental Versus Genetic and Epigenetic Influences on Growth, Metabolism and Cognitive Function in Offspring of Mothers with Type 1 Diabetes) study, which is a prospective follow-up study focusing on pregnancies complicated by maternal type 1 diabetes. We carried out a nationwide combined clinical and register-based cohort study of mortality rates and hospital admissions in mothers with diabetes $(n=986)$ who gave birth between 1992 and 2000. Control mothers $(n=91,441)$ were women from the background population, matched according to age and year of childbirth. Age at follow-up was 32-66 years.

Results Mortality rate was increased threefold in mothers with diabetes compared with control mothers (HR 3.41 [95\% CI 2.42, 4.81]; $p<0.0001$ ), and was also increased with pre-gestational kidney dysfunction (normoalbuminuria, HR 2.17 [95\% CI 1.28, 3.68]; microalbuminuria, HR 3.36 [95\% CI 0.82, 13.8]; macroalbuminuria, HR 12.9 [95\% CI 5.45, 30.7]). Moreover, the presence of hypertension prior to or at any time during pregnancy and of pre-eclampsia also increased mortality rate (hypertension, HR 4.34 [95\% CI 2.13, 8.84]; pre-eclampsia, HR 5.55 [95\% CI 2.71, 11.4]). Mortality rate also increased with higher levels of $\mathrm{HbA}_{1 \mathrm{c}}$ in early pregnancy $\left(\mathrm{HbA}_{1 \mathrm{c}} \leq 75 \mathrm{mmol} / \mathrm{mol}[\leq 9 \%]\right.$, HR 2.15 [95\% CI 1.31, 3.53]; $\mathrm{HbA}_{1 \mathrm{c}}>75 \mathrm{mmol} / \mathrm{mol}[>9 \%], \mathrm{HR}$ $6.10\left[95 \%\right.$ CI 2.67, 14.0]). However, in mothers with diabetes and $\mathrm{HbA}_{1 \mathrm{c}}<64 \mathrm{mmol} / \mathrm{mol}(<8 \%)$ in the first trimester and normal pre-gestational urinary albumin excretion rate $(n=517)$, mortality rate was comparable with that of control mothers. Among mothers with diabetes, mortality rate was associated with $\mathrm{HbA}_{1 \mathrm{c}}$ level: per $11 \mathrm{mmol} / \mathrm{mol}$ (1 percentage point) increase in $\mathrm{HbA}_{1 \mathrm{c}}$, HR was 1.52 (95\% CI 1.19, 1.94; $p=0.001)$. In mothers with diabetes, the overall incidence of hospital admissions was more than double (incidence rate ratio [IRR] $2.69[95 \%$ CI 2.59, 2.80]; $p<0.0001$ ) that of control mothers, as were admissions with
\end{abstract}

Electronic supplementary material The online version of this article (https://doi.org/10.1007/s00125-018-4575-5) contains peer-reviewed but unedited supplementary material, which is available to authorised users.

Sine Knorr

sine.knorr@clin.au.dk

1 Department of Endocrinology and Internal Medicine, Aarhus University Hospital, Nørrebrogade 44, 8000 Aarhus C, Denmark

2 Department of Molecular Medicine, Aarhus University Hospital, Aarhus, Denmark

3 Section for Epidemiology, Department of Public Health, Aarhus University, Aarhus, Denmark

4 Center for Pregnant Women with Diabetes, Department of Obstetrics, Rigshospitalet, Copenhagen, Denmark
5 Institute of Clinical Medicine, Faculty of Health and Medical Sciences, University of Copenhagen, Copenhagen, Denmark

6 Department of Endocrinology, Odense University Hospital, Odense, Denmark

7 Department of Gynaecology and Obstetrics, Nordsjællands Hospital, Hillerød, Denmark

8 Department of Growth and Reproduction, Rigshospitalet, Copenhagen, Denmark

9 Center for Pregnant Women with Diabetes, Department of Endocrinology, Rigshospitalet, Copenhagen, Denmark 


\section{Research in context}

\section{What is already known about this subject?}

- Type 1 diabetes mellitus is associated with increased morbidity and mortality rates

- Presence of diabetic complications and poor glycaemic control influences survival rate

- Long-term survival and risk of hospitalisation for mothers with diabetes is unknown

\section{What is the key question?}

- Do mortality and morbidity rates differ in mothers with type 1 diabetes compared with control mothers, and do the level of albuminuria prior to pregnancy, presence of hypertension, pre-eclampsia and periconceptional $\mathrm{HbA}_{1 c}$ predict future mortality and morbidity?

\section{What are the new findings?}

- Mothers with type 1 diabetes have a two- to threefold increase in mortality and morbidity rates

- $\quad \mathrm{HbA}_{1 c}$, the level of albuminuria around the time of conception and the presence of hypertension and pre-eclampsia are important risk factors for mortality and morbidity in type 1 diabetes

- In mothers with type 1 diabetes who achieved $\mathrm{HbA}_{1 \mathrm{c}}<64 \mathrm{mmol} / \mathrm{mol}(<8 \%)$ and had no kidney complications, mortality rate was similar to that of control mothers from the background population

\section{How might this impact on clinical practice in the foreseeable future?}

- The results of this study should encourage clinicians to focus on prevention of kidney disease and achievement of good glycaemic control already at the time of pregnancy to reduce long-term mortality and morbidity rates among mothers with type 1 diabetes

various diagnoses from 14 out of 19 ICD-10 chapters. Among mothers with diabetes, the IRR for hospital admissions increased with the level of $\mathrm{HbA}_{1 \mathrm{c}}$ : per $11 \mathrm{mmol} / \mathrm{mol}$ (1 percentage point) increase in $\mathrm{HbA}_{1 \mathrm{c}}$, HR was 1.07 (95\% CI 1.04, 1.10; $\left.p<0.0001\right)$. Conclusions/interpretation Overall, mothers with type 1 diabetes have a two- to threefold increase in mortality and morbidity rates. $\mathrm{HbA}_{1 \mathrm{c}}$ levels, level of albuminuria around the time of conception, and the presence of hypertension and pre-eclampsia are important risk factors for mortality/morbidity in this cohort. However, it is reassuring that mothers with type 1 diabetes without kidney complications and with $\mathrm{HbA}_{1 \mathrm{c}}<64 \mathrm{mmol} / \mathrm{mol}(<8 \%)$ in early pregnancy have a similar survival potential during the period where they are raising their children to that of control mothers from the background population.

Keywords Albuminuria $\cdot \mathrm{HbA}_{1 \mathrm{c}} \cdot$ Hypertension $\cdot$ Maternal $\cdot$ Morbidity $\cdot$ Mortality $\cdot$ Pre-eclampsia $\cdot$ Type 1 diabetes

\section{Abbreviations \\ IRR Incidence rate ratio \\ UAER Urinary albumin excretion rate}

\section{Introduction}

Type 1 diabetes mellitus is associated with increased morbidity and mortality rates, primarily as a result of acute and chronic complications due to hyperglycaemia. In daily clinic, women with type 1 diabetes who are able to conceive and give birth to a living infant are considered to have better glycaemic control and be among the healthier group of individuals with type 1 diabetes. In addition, the treatment of type 1 diabetes has improved immensely with the introduction of self-monitored blood glucose, $\mathrm{HbA}_{1 \mathrm{c}}$ measurements, use of statins and prevention of kidney failure through the use of ACE inhibitors [1-4]. The most recent studies report HRs for mortality in individuals with type 1 diabetes to be between 3.5 and 18.3 [5-9]. The presence of late diabetic complications, such as kidney disease, has a large impact on survival, and a difference between sex is seen, with higher HRs for women than for men [6-10]. No studies have looked into the long-term survival rate of an unselected cohort of mothers with diabetes, covering the period when they raise their children to adulthood.

An increased risk of death from cardiovascular disease, infections and metabolic complications has been described, along with risk of violent death (fatal accidents, suicide, intoxication) and death from other causes [9-13]. In particular, 
ischaemic heart disease has previously been described as a frequent cause of death among young women ( $<40$ years) with type 1 diabetes [12]. It is not known whether this is also the case in mothers with type 1 diabetes receiving modern treatment.

Individuals with type 1 diabetes have an increased risk of hospitalisation owing to complications of type 1 diabetes (e.g. hypoglycaemia, ketoacidosis), but whether young mothers have an increased incidence of hospitalisation owing to infections, asthma, cancer and psychiatric diagnosis is not known [14-18].

Therefore, the aim of this study was to examine the longterm mortality rates and risk of hospitalisation after childbirth in a recent nationwide cohort of mothers with type 1 diabetes. Mortality rate and the risk of hospitalisation, both overall and cause-specific, and in relation to kidney disease prior to pregnancy and $\mathrm{HbA}_{1 \mathrm{c}}$ levels in early pregnancy, were evaluated.

\section{Methods}

Study design, setting and participants From 1992 to 2000, pregnant Danish women with type 1 diabetes were prospectively added to a national registry managed by the Danish Diabetes Association. Information regarding diabetes status and pregnancy outcome was registered by obstetricians at the eight hospitals in Denmark which were responsible for antenatal care and delivery of pregnant women with type 1 diabetes. Coverage of cases from the reporting centres was between $75 \%$ and $93 \%$, as previously described [19].

We identified women with type 1 diabetes in the Danish Civil Registration System who gave birth between 1992 and 2000. These women were included as index mothers $(n=$ 986), and the inclusion criterion was delivery of a live-born child after 24 weeks of gestation. Statistics Denmark identified approximately 100 control mothers $(n=91,441)$ in the Danish Civil Registration System for each index mother. The matching criteria were: control mothers and index mothers born the same year, and the control mothers giving birth to a live-born child of the same sex within \pm 90 days of the index mother. Matching was done by the greedy matching technique [20]. We retrieved information regarding emigration for both groups. Individuals who had emigrated during the observation period were excluded from further analyses after the emigration date. We did not exclude index or control mothers with chronic diseases. This study is a part of the EPICOM (Environmental Versus Genetic and Epigenetic Influences on Growth, Metabolism and Cognitive Function in Offspring of Mothers with Type 1 Diabetes) study (ClinicalTrials.gov registration no. NCT01559181). Information concerning the children of these mothers and details about the study has previously been published [21].
For a total of 862 index mothers, it was possible to retrieve additional information from the Danish Diabetes Association registry (Table 1). The level of albuminuria prior to pregnancy was reported for 728 mothers and was defined as: normoalbuminuria (urinary albumin excretion rate [UAER] $\leq 30 \mathrm{mg} / 24 \mathrm{~h}$ or $\leq 20 \mu \mathrm{g} / \mathrm{min}$ ), microalbuminuria (UAER between 30 and $300 \mathrm{mg} / 24 \mathrm{~h}$ or between 20 and $200 \mu \mathrm{g} / \mathrm{min}$ ) and macroalbuminuria (UAER $\geq 300 \mathrm{mg} / 24 \mathrm{~h}$ or $\geq 200 \mu \mathrm{g} / \mathrm{min}$ ). One pre-gestational $\mathrm{HbA}_{1 \mathrm{c}}$ measurement and one measurement per trimester were reported to the registry. Local assays were used and correction was made to a common standard, as described previously [22]. We were able to retrieve first trimester $\mathrm{HbA}_{1 \mathrm{c}}$ measurements for 828 pregnancies; pre-gestational $\mathrm{HbA}_{1 \mathrm{c}}$ measurements served as a surrogate in 20 pregnancies. Hypertension was defined as BP $>140 / 90 \mathrm{mmHg}$ or treatment with antihypertensive drugs prior to or during pregnancy and was reported for 748 mothers with type 1 diabetes. Information on preeclampsia, which was defined as blood pressure $>140$ / $90 \mathrm{mmHg}$ and proteinuria $2+$ on a urine protein test strip (equal to $1.0 \mathrm{~g} / \mathrm{l}$ ) before 20 gestational weeks (the common definition in Denmark at the time of the registry), could be retrieved for 811 mothers. There were no specific criteria for the diagnosis of pre-eclampsia in women with diabetic nephropathy (with or without hypertension); it was up to the decision of the reporting clinician. However, at the time of the registry, the following principles were often used in Denmark: in women with diabetic nephropathy the preeclampsia diagnosis was based on the same findings as mentioned above accompanied by a sudden increase of $\geq 15 \%$ in systolic or diastolic BP.

Mortality and hospital admissions Information on deaths was retrieved from the Danish Register of Causes of Death [23]. Prior to 1994, diagnoses were classified according to ICD-8, and from 1994 according to ICD-10 (www.who.int/ classifications/icd/en/). ICD-8 diagnoses were translated to ICD-10, and for cause-specific mortality, these diagnoses were categorised into 19 chapters.

Discharge diagnoses describing the primary reason for hospital admission were retrieved from the Danish National Hospital Register, which includes nationwide data on all somatic hospital admissions since 1977, and from 1995 it also includes data on outpatient visits [24]. From the Danish Psychiatric Central Research Register we retrieved information about diagnoses given within the psychiatric system; since there are no private psychiatric hospitals in Denmark, this registry may be considered virtually complete for hospitalised mental disorders [25]. The discharge diagnoses served as a measure of overall and causespecific morbidity, as described for mortality. Both registers used ICD-8 prior to 1994 and ICD-10 from 1994 and onwards. 
Table 1 Characteristics of mothers with pre-gestational type 1 diabetes (index mothers) and matched control mothers

\begin{tabular}{|c|c|c|}
\hline $\begin{array}{l}\text { Characteristic } \\
n\end{array}$ & $\begin{array}{l}\text { Index mothers } \\
986\end{array}$ & $\begin{array}{l}\text { Control mothers } \\
91,441\end{array}$ \\
\hline Bachelor's degree at follow-up & $319(32)$ & $31,899(35)$ \\
\hline Maternal age at childbirth, years & $29.2(18-47)$ & $29.1(18-47)$ \\
\hline Maternal age at follow-up, years & $46.5(33-67)$ & $46.5(33-67)$ \\
\hline \multicolumn{3}{|l|}{ Baseline characteristics } \\
\hline Duration of diabetes, years $(n=853)$ & $12.6(0-36)$ & - \\
\hline \multicolumn{3}{|l|}{ Pre-gestational $\mathrm{HbA}_{1 \mathrm{c}}(n=695)$} \\
\hline $\mathrm{mmol} / \mathrm{mol}$ & $63(21-143)$ & - \\
\hline$\%$ & $7.9(4.1-15.2)$ & \\
\hline \multicolumn{3}{|l|}{ First trimester $\mathrm{HbA}_{1 \mathrm{c}}(n=828)$} \\
\hline $\mathrm{mmol} / \mathrm{mol}$ & $58(21-119)$ & - \\
\hline$\%$ & $7.5(4.1-13.0)$ & \\
\hline \multicolumn{3}{|l|}{ Second trimester $\mathrm{HbA}_{1 \mathrm{c}}(n=821)$} \\
\hline $\mathrm{mmol} / \mathrm{mol}$ & $50(22-103)$ & - \\
\hline$\%$ & $6.7(4.2-11.6)$ & \\
\hline \multicolumn{3}{|l|}{ Third trimester $\mathrm{HbA}_{1 \mathrm{c}}(n=842)$} \\
\hline $\mathrm{mmol} / \mathrm{mol}$ & $51(21-110)$ & - \\
\hline$\%$ & $6.8(4.1-12.2)$ & \\
\hline \multicolumn{3}{|l|}{ Pre-gestational albuminuria } \\
\hline Normoalbuminuria & $616(62)$ & - \\
\hline Microalbuminuria & $67(7)$ & - \\
\hline Macroalbuminuria & $45(5)$ & - \\
\hline Status unknown & $258(26)$ & - \\
\hline \multicolumn{3}{|l|}{ Pre-gestational retinopathy } \\
\hline No retinopathy & $485(49)$ & - \\
\hline Simplex & $235(24)$ & - \\
\hline Proliferative & $51(5)$ & - \\
\hline Status unknown & $215(22)$ & - \\
\hline \multicolumn{3}{|l|}{ Pre-gestational hypertension } \\
\hline$\leq 140 / 90 \mathrm{mmHg}$ & $701(71)$ & - \\
\hline$>140 / 90 \mathrm{mmHg}$ & $9(1)$ & - \\
\hline Antihypertensive treatment & $46(5)$ & - \\
\hline Status unknown & $230(23)$ & - \\
\hline \multicolumn{3}{|l|}{ Pre-eclampsia ${ }^{\mathrm{a}}$} \\
\hline No pre-eclampsia & $647(66)$ & - \\
\hline Pre-eclampsia & $164(17)$ & - \\
\hline Status unknown & $175(18)$ & - \\
\hline Pre-gestational BMI, $\mathrm{kg} / \mathrm{m}^{2}(n=823)$ & $23.6(17.8-42.3)$ & - \\
\hline
\end{tabular}

Data are presented as mean (range) or number (\%)

Baseline data is not available for mothers in the control group since they were matched at follow-up and not monitored during pregnancy

${ }^{\text {a }}$ Pre-eclampsia was defined as BP $>140 / 90 \mathrm{mmHg}$ and proteinuria $2+$ on a urine protein test strip (equal to $1.0 \mathrm{~g} / \mathrm{l}$ ) before 20 gestational weeks
Education The educational status of the index and control mothers at follow-up was retrieved from Statistics Denmark. The mothers were classified as either having or not having completed an education to bachelor's degree level. As there was no information regarding the educational status of 1240 mothers $(1.3 \%)$, it was classified as missing.

Statistical analysis We estimated HRs for mortality using stratified Cox regression with each index mother and the matched 
control mothers as a stratum. When performing stratified Cox regression, the date of entry was the date of childbirth; individuals were censored at the date of emigration or the last date of registration, 31 December 2012. The date of death was updated to 31 December 2012, but the Register of Causes of Death was only updated to 31 December 2011. Hospital admissions were analysed by mixed-effects negative binomial regression yielding incidence rate ratios (IRRs) as the measure of association. These data are clustered at two levels. First, the data for each mother at hospital admission constituted a cluster, and we allowed for this clustering by using a randomeffects model. Second, each index mother and the matched control mothers constituted a cluster, and we allowed for this clustering by using robust variance estimates. We used negative binomial regression rather than Poisson regression to allow for over-dispersion. This method is computationally demanding, and we restricted the number of control mothers per index mother to ten, selected at random, with negligible loss of precision. We calculated HRs and IRRs with and without adjustment for educational level.

For hospital admissions, we made two supplementary analyses. The risk of ever being admitted was analysed using conditional logistic regression, and the incidence of admissions among mothers who were ever admitted was analysed using mixed-effects negative binomial regression.

The associations between the levels of albuminuria, $\mathrm{HbA}_{1 \mathrm{c}}$, hypertension, pre-eclampsia, mortality rate and hospital admissions were analysed after dividing the index mothers and the matched control mothers into groups according to the index mothers' level of albuminuria prior to pregnancy, hypertension either prior to or during pregnancy, pre-eclampsia, and $\mathrm{HbA}_{1 \mathrm{c}}$ in early pregnancy $\left(\mathrm{HbA}_{1 \mathrm{c}}>75 \mathrm{mmol} / \mathrm{mol}\right.$ [ $>9 \%$ ], indicating poor control, or $\leq 75 \mathrm{mmol} / \mathrm{mol}[\leq 9 \%$ ], indicating adequate control). Mortality rate was further analysed for index mothers with normoalbuminuria. These mothers were grouped according to $\mathrm{HbA}_{1 \mathrm{c}}$ in early pregnancy $(<52 \mathrm{mmol} /$ $\mathrm{mol}[<6.9 \%$ ], 52-63 mmol $/ \mathrm{mol}$ [6.9-7.9\%], 64-75 mmol $/ \mathrm{mol}$ [8-9\%] or $>75 \mathrm{mmol} / \mathrm{mol}$ [ $>9 \%]$ ) and mortality rate was compared with that of the matched control mothers.

We studied associations between the levels of albuminuria and $\mathrm{HbA}_{1 \mathrm{c}}$ and mortality rate and hospital admissions solely among mothers with diabetes. $\mathrm{HbA}_{1 \mathrm{c}}$, onset of diabetes and maternal age at follow-up were included as continuous variables, while the level of albuminuria was analysed in groups using mothers with normoalbuminuria as a reference. Test for trend in albuminuria was performed with albuminuria as a continuous variable for both HR and IRR. The calculated HRs and IRRs for $\mathrm{HbA}_{1 \mathrm{c}}$ correspond to an $11 \mathrm{mmol} / \mathrm{mol}$ (1 percentage point) increase.

Statistical analyses were made in Stata 13.1 for Windows (StataCorp LP, College Station, TX, USA); $p$ values $<0.05$ were considered significant. The study was approved by the Danish Data Protection Agency. Since the study was register-

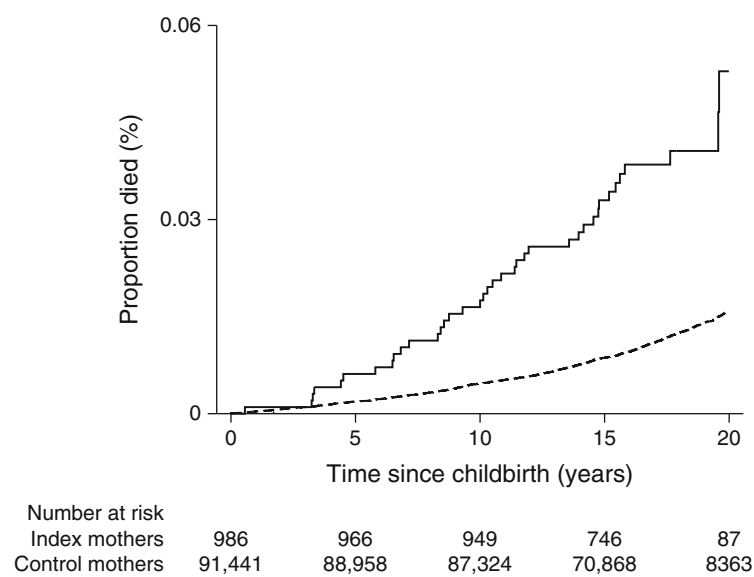

Fig. 1 Kaplan-Meier plot showing overall mortality rate among mothers with type 1 diabetes (index mothers) and matched control mothers. Solid line, index mothers; dashed line, control mothers

based and therefore anonymous, informed consent was not required. However, the women with type 1 diabetes included in the original Danish Diabetes Association registry gave informed consent on inclusion.

\section{Results}

Mortality rate in mothers with type 1 diabetes compared with matched control mothers A total of 986 mothers with diabetes were included in the study along with 91,441 matched control mothers. Of these, 38 mothers with diabetes and 1049 control mothers died during the observation period.

Mortality rate was significantly increased in mothers with diabetes (HR 3.41 [95\% CI 2.42, 4.81]; $p<0.0001$ ) (Fig. 1, Table 2). The specific cause of death was known for 963 individuals, and cause-specific mortality rates could be estimated for ten of 19 ICD-10 chapters (Table 2). The most frequent causes of death are listed in electronic supplementary material (ESM) Table 1.

Mortality in relation to albuminuria, hypertension, preeclampsia and $\mathrm{HbA}_{1 \mathrm{c}}$ level In mothers with diabetes, we had information on the pre-gestational level of albuminuria for $74 \%$, on hypertension prior to or during pregnancy for $76 \%$, on pre-eclampsia for $82 \%$ and on knowledge of the first trimester level of $\mathrm{HbA}_{1 \mathrm{c}}$ for $84 \%$. Of the deceased mothers with diabetes, nine had $\mathrm{HbA}_{1 \mathrm{c}}>75 \mathrm{mmol} / \mathrm{mol}(>9 \%)$, six had macroalbuminuria, two had microalbuminuria, eight had hypertension and nine were diagnosed with pre-eclampsia. Some mothers with diabetes were represented in more than one subgroup.

There was a close relation between the level of albuminuria and mortality rate, but even type 1 diabetic mothers with normoalbuminuria had significantly increased mortality rate 


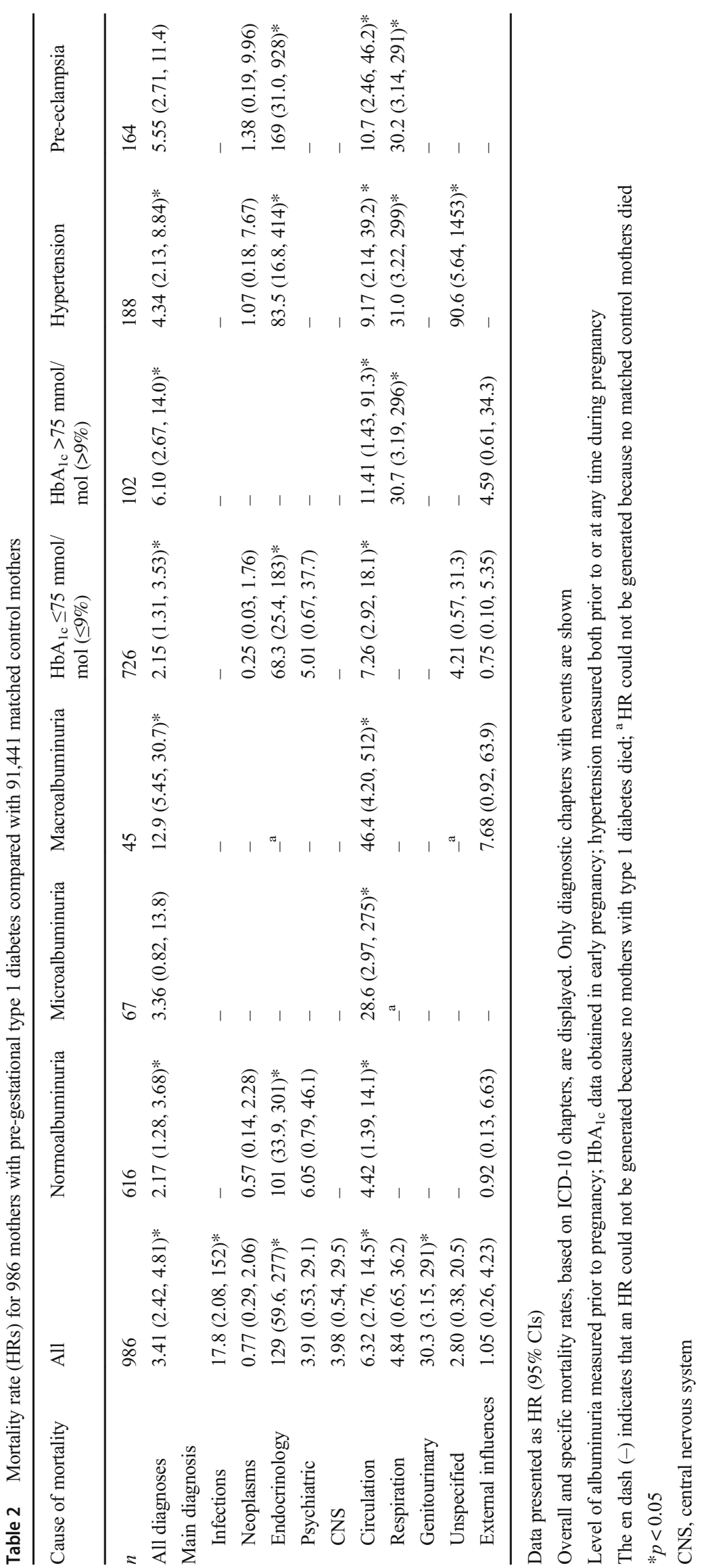


compared with the matched control mothers (Table 2). The same applied to the presence of hypertension and preeclampsia (Table 2). Similarly, we found increasing mortality rate with increasing $\mathrm{HbA}_{1 \mathrm{c}}$ in index compared with control mothers (Table 2). Compared with matched control mothers, mortality rate was also increased in the group of mothers with type 1 diabetes and no information on the level of albuminuria, hypertension, pre-eclampsia or $\mathrm{HbA}_{1 \mathrm{c}}$ (ESM Table 2). Only in the group of mothers with diabetes who had normoalbuminuria prior to pregnancy and $\mathrm{HbA}_{1 \mathrm{c}}$ below $64 \mathrm{mmol} / \mathrm{mol}(8 \%)$ in the first trimester $(n=517)$ was mortality rate not significantly increased compared with control mothers (Table 3 ). Mothers with diabetes, normoalbuminuria and $\mathrm{HbA}_{1 \mathrm{c}}<52 \mathrm{mmol} / \mathrm{mol}(<6.9 \%)$ had an HR of $1.11(95 \%$ CI $0.36,3.47)$, mothers with normoalbuminuria and $\mathrm{HbA}_{1 \mathrm{c}}$ $52-63 \mathrm{mmol} / \mathrm{mol}(6.9-7.9 \%)$ had an HR of $1.53(95 \%$ CI $0.57,4.11)$ and mothers with normoalbuminuria and $\mathrm{HbA}_{1 \mathrm{c}}$ 64-75 $\mathrm{mmol} / \mathrm{mol}(8-9 \%)$ had an HR of 4.02 (95\% CI 1.64, $9.84)$, whereas mortality rate in the group of mothers with normoalbuminuria and $\mathrm{HbA}_{1 \mathrm{c}}>75 \mathrm{mmol} / \mathrm{mol}(>9 \%)$ was increased with an HR of 3.64 (95\% CI 1.15, 11.6) (Table 3).

Using mothers with normoalbuminuria as a reference, the HR in diabetic mothers with microalbuminuria was 1.07 (95\% CI $0.24,4.76)$ and $4.76(95 \%$ CI $1.73,13.1)$ in mothers with macroalbuminuria, and this trend was significant $(p=0.006)$.

Mortality rate was associated with the level of $\mathrm{HbA}_{1 \mathrm{c}}$ among mothers with diabetes; per $11 \mathrm{mmol} / \mathrm{mol}$ (1 percentage point) increase in $\mathrm{HbA}_{1 \mathrm{c}}$, HR was 1.52 (CI 1.19, 1.94; $p=0.001$ ). For deaths related to circulatory diseases (e.g. heart failure or acute myocardial infarction) and endocrine diseases (e.g. type 1 diabetic complications), we found increased mortality rate with increasing $\mathrm{HbA}_{1 \mathrm{c}}$, and for endocrine diseases mortality rate also increased with increasing levels of albuminuria.
Incidence of hospital admissions in mothers with type 1 diabetes compared with matched control mothers The overall incidence of hospital admissions was significantly increased in mothers with diabetes compared with matched control mothers (IRR 2.69 [95\% CI 2.59, 2.80]; $p<0.0001$ ) (Fig. 2, ESM Tables 3-6). The incidence of admissions was increased for several ICD-10 chapters, including endocrine diseases, eye diseases, infections, central nervous system diseases, circulatory diseases and genitourinary diseases. We also found an elevated risk of ever being admitted with diseases of the blood and immune system, psychiatric diseases, respiratory diseases, skin and musculoskeletal diseases, as well as pregnancy-associated diseases, unspecified diseases and admissions due to external influences (e.g. car accident, falling, exposure to fire). Altogether, mothers with diabetes had an increased risk of hospital admissions with diagnoses from 14 out of 19 ICD-10 chapters compared with control mothers.

When excluding admissions with diagnoses relating to endocrine and eye diseases, the overall incidence of hospital admissions was still increased in mothers with diabetes compared with control mothers (IRR 1.71 [95\% CI 1.64, 1.78]; $p<0.0001$ ) (Fig. 2).

Most of the increased IRRs are explained by an increased proportion of mothers with diabetes ever admitted rather than by a higher number of admissions among those ever admitted (ESM Table 7). When excluding all outpatient and emergency room visits, we still found an increased risk of admissions (HR 2.38 [95\% CI 2.20, 2.57]; $p<0.0001$ ), and the risk of admissions with specific diagnoses was increased in 15 out of 19 ICD-10 chapters (ESM Table 8).

Table 3 Mortality rate (HRs) for mothers with pre-gestational type 1 diabetes and normoalbuminuria prior to pregnancy $(n=717)$, according to $\mathrm{Hb}_{1 \mathrm{c}}$ during early pregnancy, compared with matched control mothers

\begin{tabular}{|c|c|c|c|c|}
\hline $\begin{array}{l}\text { Cause of } \\
\text { mortality }\end{array}$ & $\begin{array}{l}\mathrm{HbA}_{1 \mathrm{c}}<52 \mathrm{mmol} / \\
\mathrm{mol}(<6.9 \%)\end{array}$ & $\begin{array}{l}\mathrm{HbA}_{1 \mathrm{c}} \geq 52 \mathrm{mmol} / \mathrm{mol}(\geq 6.9 \%) \\
\text { and }<64 \mathrm{mmol} / \mathrm{mol}(<8 \%)\end{array}$ & $\begin{array}{l}\mathrm{HbA}_{1 \mathrm{c}} \geq 64 \mathrm{mmol} / \mathrm{mol}(\geq 8 \%) \\
\text { and } \leq 75 \mathrm{mmol} / \mathrm{mol}(\leq 9 \%)\end{array}$ & $\begin{array}{l}\mathrm{HbA}_{1 \mathrm{c}}>75 \mathrm{mmol} / \\
\mathrm{mol}(>9 \%)\end{array}$ \\
\hline Mothers with T1D, $n$ & 276 & 241 & 122 & 78 \\
\hline All diagnoses & $1.11(0.36,3.47)$ & $1.53(0.57,4.11)$ & $4.02(1.64,9.84)^{*}$ & $3.64(1.15,11.6)^{*}$ \\
\hline \multicolumn{5}{|l|}{ Main diagnosis } \\
\hline Neoplasms & - & $0.69(0.10,4.91)$ & - & - \\
\hline Endocrinology & $58.9(9.83,352)^{*}$ & $17.0(1.98,145)^{*}$ & $184(16.7,2036) *$ & - \\
\hline Psychiatric & - & $11.6(1.42,94.8)^{*}$ & - & - \\
\hline Circulation & - & $3.43(0.47,25.3)$ & $27.6(7.58,100)^{*}$ & - \\
\hline External influences & $2.39(0.33,17.4)$ & - & - & - \\
\hline
\end{tabular}

Data presented as HR (95\% CIs)

Overall and specific mortality rates, based on ICD-10 chapters, are displayed. Only diagnostic chapters with events are shown

$* p<0.05$

T1D, type 1 diabetes

The en dash (-) indicates that an HR could not be generated because no mothers with type 1 diabetes died 
Fig. 2 Forest plot displaying IRRs for hospital admissions, according to primary diagnosis, for mothers with pre-gestational type 1 diabetes compared with matched control mothers. As mothers with type 1 diabetes are followed in outpatient clinics and, therefore, have many more visits to endocrine and eye clinics, IRRs for endocrine and eye diseases have been omitted but are reported in ESM Tables 4 and 5. Data on the ICD-10 chapters of congenital malformations and perinatal disease are not shown

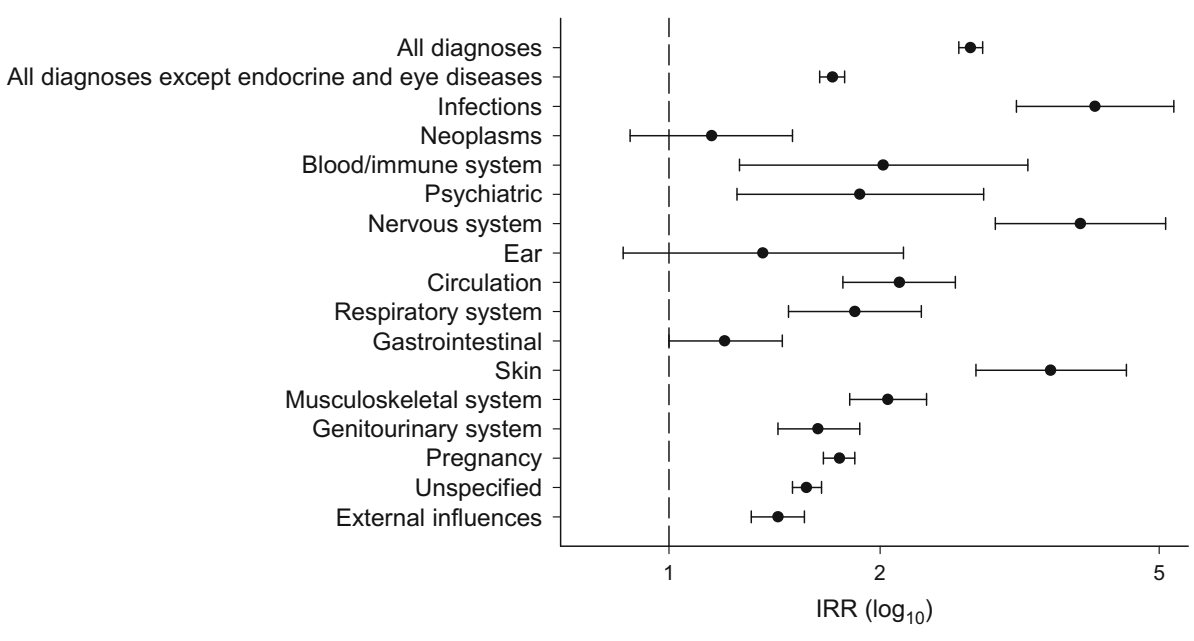

Incidence of hospital admissions in relation to albuminuria, hypertension, pre-eclampsia and $\mathrm{HbA}_{1 c}$ levels In diabetic mothers we found an increased risk of hospital admissions with increasing levels of albuminuria compared with matched control mothers (ESM Table 3). In particular, the risk of admission with infections, endocrine, eye, circulatory, skin and unspecified diseases, as well as diseases caused by external influences, was consistently associated with the level of albuminuria prior to pregnancy (ESM Table 3).

When analysing the incidence of hospital admissions among mothers with diabetes, using mothers with normoalbuminuria as a reference, we found a trend towards an increased incidence with increasing level of albuminuria: microalbuminuria, IRR 1.09 (95\% CI 0.94, 1.28); macroalbuminuria, IRR 1.18 (95\% CI 0.98, 1.42); test for trend, $p=0.051$ (data not shown).

In diabetic mothers the presence of hypertension and preeclampsia was also found to be associated with an increased risk of being admitted both overall and for diagnoses from several ICD-10 chapters, including infections, endocrinology, eye and circulatory diseases (ESM Tables 4 and 5).

With increasing levels of $\mathrm{HbA}_{1 \mathrm{c}}$ in early pregnancy, we found an overall increasing risk of being admitted to hospital in diabetic mothers compared with control mothers (ESM Table 6).

Among mothers with diabetes, we found an IRR for hospital admissions of 1.07 per $11 \mathrm{mmol} / \mathrm{mol}$ ( 1 percentage point) increase in $\mathrm{HbA}_{1 \mathrm{c}}(95 \%$ CI $1.04,1.10 ; p<0.0001)$. Admissions with diagnoses from the following ICD-10 chapters increased significantly with $\mathrm{HbA}_{1 \mathrm{c}}$ : infections, endocrine, eye, skin, musculoskeletal, genitourinary, external influences and unspecified diseases (data not shown).

Education Fewer mothers with type 1 diabetes had a bachelor's degree (Table 1). However, when adjusting for education, the estimates of mortality and hospital admission rates remained largely unchanged (data not shown).

\section{Discussion}

In this nationwide unselected cohort of 986 mothers with type 1 diabetes who gave birth during the 1990s, the risk of death from any cause over the next two decades was more than three times that of age- and childbirth-matched mothers from the background population. Mothers with diabetes had an increased risk of dying mainly from endocrine, genitourinary, infectious and circulatory diseases. The presence of diabetic nephropathy at baseline was found to be a strong indicator of mortality risk. $\mathrm{HbA}_{1 \mathrm{c}}$ level in early pregnancy was associated with increased long-term mortality rates, and among mothers with the poorest glycaemic control the risk of death was increased more than sixfold compared with control mothers.

However, in the group of mothers with $\mathrm{HbA}_{1 \mathrm{c}}<64 \mathrm{mmol} /$ mol $(<8 \%)$ and no kidney dysfunction, mortality rate was similar to that of matched control mothers during the important time when they were raising their children to adulthood. This is an important message for young women with diabetes.

As a surrogate marker of morbidity, the risk of mothers with type 1 diabetes being admitted to hospital was more than twice that of control mothers. Besides admissions related to diabetes (e.g. endocrine and eye diseases), we found an elevated risk of admission with diagnoses from almost all ICD10 chapters. Even after excluding admissions directly related to diabetes, the overall incidence of admissions was increased. This illustrates that type 1 diabetes has a global impact on general somatic and mental health.

The results of the present study of mothers with diabetes are in line with the results from previous studies on mortality rates in individuals with type 1 diabetes $[5-7,9,26]$, and in addition this study includes detailed data on morbidity patterns. Like earlier published studies, we found mortality rates to increase with levels of albuminuria [5-7]. Our study, in line with that of Lind et al [5], found that mortality rate was twice as high among type 1 diabetic mothers with 
normoalbuminuria compared with matched control mothers, despite the fact that our cohort of mothers with diabetes was relatively young and might have benefitted from the use of ACE inhibitors over the last 20 years.

Several studies have shown an association between increasing $\mathrm{HbA}_{1 \mathrm{c}}$ level and mortality rate $[5,6,27,28]$. Lind et al [5] showed a monotonic increase in mortality rate with $\mathrm{HbA}_{1 \mathrm{c}}$, starting at an $\mathrm{HbA}_{1 \mathrm{c}}$ level below $52 \mathrm{mmol} / \mathrm{mol}$ (6.9\%), and the DCCT/Epidemiology of Diabetes Interventions and Complications (EDIC) trial [28] from $75 \mathrm{mmol} / \mathrm{mol}(9 \%)$ and with a significant increase in mortality rate for women with $\mathrm{HbA}_{1 \mathrm{c}}>75 \mathrm{mmol} / \mathrm{mol}(>9 \%)$ in comparison with men. Our study supplements these findings and further supports the importance of good glycaemic control by presenting morbidity results with an increasing risk of admission with increasing $\mathrm{HbA}_{1 \mathrm{c}}$, both overall and for most ICD-10 chapters.

Taking into account the modest number of deaths among the mothers with type 1 diabetes, any conclusions about changes in the cause of deaths would be vague. However, our results still show an increase in deaths from endocrine diseases (e.g. diabetic complications or ketoacidosis), genitourinary and circulatory diseases. In particular, deaths related to circulatory diseases seem to increase with level of kidney dysfunction. Therefore, focusing on preventing kidney disease among young women with type 1 diabetes is of utmost importance.

We did not find an increased risk of admission with increasing level of albuminuria, with the exception of admissions due to circulatory diseases. We did expect a pattern of an overall increased number of hospital admissions with decreasing kidney function, but improved antihypertensive treatment with inhibitors of the renin-angiotensin system in recent years might have improved the health of these women [29].

The present study has several strengths. The mothers with diabetes were all included in the cohort by the primary care physician responsible for their care during pregnancy. This, along with cross-checks with local discharge and insulin prescription registries, ensured exclusion of women with type 2 diabetes or gestational diabetes [19]. This is an advantage compared with other registry-based studies, where the diagnosis of type 1 diabetes is often defined as diabetes onset before the age of 30 and use of insulin. The validity of the results of some registry-based mortality studies is therefore limited, as individuals with type 2 diabetes might have been included in the studies $[9,11,12]$. We had extensive clinical information on mothers with diabetes and their pregnancies, and from Statistics Denmark we had national registry data on mortality, hospital admissions and education. The clinical data was collected during the 1990s and is confined by the methods available at the time. In particular, the methods of diagnosis of pre-eclampsia in women with existing nephropathy and the use of urine protein test strips can be seen as a weakness of the study.
Access to a cohort of women with type 1 diabetes who had never been pregnant could have further strengthened our study. However, such women might very well differ from ours in respect to poorer health resulting in a reduced ability to become pregnant [30].

Prior studies have shown that the positive predictive value of discharge diagnoses from the Danish National Hospital Register ranges between $66 \%$ and $83 \%$, and this may give rise to bias of some of estimates in our study [24]. However, we used the discharge diagnoses at a chapter level and have no reason to assume that the validity of diagnoses given to mothers with diabetes and the control mothers differed, and therefore we regard this as a minor problem.

The focus on pregnancy in women with diabetes, and especially on pregnancies further complicated by kidney disease, hypertension, pre-eclampsia or high $\mathrm{HbA}_{1 \mathrm{c}}$, obviously meant that medical professionals offered, and women with diabetes sought, medical help at a lower threshold compared with control women. We expect that this could have affected the incidence of hospital visits among mothers with diabetes, but not their mortality rates. During the 1990s when our cohort gave birth, an $\mathrm{HbA}_{1 \mathrm{c}}$ level below $53 \mathrm{mmol} / \mathrm{mol}(7 \%)$ during pregnancy was considered acceptable glycaemic control. However, as a result of more recent guidelines, we expect that pregnant women with diabetes today have a lower $\mathrm{HbA}_{1 \mathrm{c}}$. In a Danish study, Secher et al [31] described tighter glycaemic control among pregnant women with type 1 diabetes between 2009 and 2011 than among the women included in our study. Therefore, we would expect the mortality and morbidity rate to be less elevated among women with type 1 diabetes who have given birth in recent years.

In conclusion, mothers with type 1 diabetes have increased mortality and morbidity rates during their offspring's childhood. This applies to mothers with normoalbuminuria and it increases with levels of albuminuria and $\mathrm{HbA}_{1 \mathrm{c}}$. The presence of hypertension and pre-eclampsia also increases both mortality and morbidity rates. In general, the pattern of diseases covers almost all groups of diagnoses, indicating the negative effect of type 1 diabetes on general health. But in the group of mothers with type 1 diabetes who achieved $\mathrm{HbA}_{1 \mathrm{c}}<64 \mathrm{mmol} /$ mol $(<8 \%)$ and had no kidney complications, mortality rate was similar to that of control mothers from the background population.

Acknowledgements The Danish Diabetes Association is acknowledged for originally assisting in the creation of a registry of pregnant women with type 1 diabetes. In addition, data collection in the original registry was performed by P. Ovesen, L. Mølsted-Pedersen, J. Klebe, N. Hahnemann, M. Møller, J. G. Westergaard, H. Gjessing, J. Kragh Mostrup, K. H. Frandsen, E. Stage, A. Thomsen, T. Lousen, K. Rubeck Petersen, B. Øvlisen, J. Kvetny and H. Poulsen (Working Group for Type 1 Diabetes Pregnancy). Apart from H. Beck-Nielsen and P. Damm, the 
original registry working group included A. Frøland, L. MølstedPedersen, J. Klebe and C. E. Mogensen.

Data availability The dataset generated and analysed during this study is not publicly available due both to considerations of the privacy and anonymity of the participants and also due to restrictions from Statistics Denmark. Other researchers may apply for access to the data if they have obtained official approval.

Funding The study was funded by the European Foundation for the Study of Diabetes/Lilly 2015 Programme and the Lundbeck Foundation.

Duality of interest SK, ZL, BB, TDC, RBJ and SJ declare that there is no duality of interest associated with their contribution to this manuscript. HB-N, PD and CHG have received lecture fees from Novo Nordisk. DMJ has received lecture fees from Eli Lilly. ERM and HB-N receive grant support from Novo Nordisk.

Contribution statement HB-N and PD contributed to the establishment of the original registry, and PD and DMJ contributed to data collection. SK, ZL, BB, TDC, RBJ, PD, ERM, HB-N, DMJ and CHG all contributed substantially to the conception and design of the study. SK, SJ and CHG analysed and interpreted the data, and SK drafted the manuscript and designed the tables. All authors critically revised the article and approved the final version for publication. SK had full access to the data and takes full responsibility for the contents of the paper.

\section{References}

1. Bojestig M, Arnqvist H, Hermansson G et al (1994) Declining incidence of nephropathy in insulin-dependent diabetes mellitus. N Engl J Med 330:15-18

2. Andrésdóttir G, Jensen ML, Carstensen B et al (2014) Improved prognosis of diabetic nephropathy in type 1 diabetes. Kidney Int $71: 1-10$

3. Mathiesen ER, Hommel E, Hansen HP et al (1999) Randomised controlled trial of long term efficacy of captopril on preservation of kidney function in normotensive patients with insulin dependent diabetes and microalbuminuria. BMJ 319:24-25

4. Lewis E, Hunsicker L, Bain R, Rohde R (1993) The effect of angiotensin-converting-enzyme on diabetic nephropathy. $\mathrm{N}$ Engl $\mathrm{J}$ Med 329:1456-1462

5. Lind M, Svensson A-M, Kosiborod M et al (2014) Glycemic control and excess mortality in type 1 diabetes. N Engl J Med 371:1972-1982

6. Groop P, Thomas MC, Moran JL et al (2009) The presence and severity of chronic kidney disease predicts all-cause mortality in type 1 diabetes. Diabetes 58:1651-1658

7. Orchard TJ, Secrest AM, Miller RG, Costacou T (2010) In the absence of renal disease, 20 year mortality risk in type 1 diabetes is comparable to that of the general population: a report from the Pittsburgh Epidemiology of Diabetes Complications Study. Diabetologia 53:2312-2319

8. Livingstone SJ, Looker HC, Hothersall EJ et al (2012) Risk of cardiovascular disease and total mortality in adults with type 1 diabetes: Scottish registry linkage study. PLoS Med 9:1-11

9. Soedamah-Muthu SS, Fuller JH, Mulnier HE et al (2006) All-cause mortality rates in patients with type 1 diabetes mellitus compared with a non-diabetic population from the UK general practice research database, 1992-1999. Diabetologia 49:660-666

10. Secrest AM, Becker DJ, Kelsey SF et al (2010) Cause-specific mortality trends in a large population-based cohort with longstanding childhood-onset type 1 diabetes. Diabetes 59:3216-3222
11. Laing SP, Swerdlow AJ, Carpenter LM et al (2003) Mortality from cerebrovascular disease in a cohort of 23000 patients with insulintreated diabetes. Stroke 34:418-421

12. Laing SP, Swerdlow AJ, Slater SD et al (2003) Mortality from heart disease in a cohort of 23,000 patients with insulin-treated diabetes. Diabetologia 46:760-765

13. Skrivarhaug T, Bangstad H-J, Stene LC et al (2006) Long-term mortality in a nationwide cohort of childhood-onset type 1 diabetic patients in Norway. Diabetologia 49:298-305

14. Donnelly J, Nair S, Griffin R et al (2016) Diabetes and insulin therapy are associated with increased risk of hospitalization for infection but not mortality: a longitudinal cohort study. Clin Infect Dis $64: 435-442$

15. Kornum JB, Thomsen RW, Riss A et al (2008) Diabetes, glycemic control, and risk of hospitalization with pneumonia. Diabetes Care 31:1541-1545

16. Cooper MN, Lin A, Alvares GA et al (2017) Psychiatric disorders during early adulthood in those with childhood onset type 1 diabetes: rates and clinical risk factors from population-based follow-up. Pediatr Diabetes 18:599-606

17. Shu X, Ji J, Li X et al (2010) Cancer risk among patients hospitalized for type 1 diabetes mellitus: a population-based cohort study in Sweden. Diabet Med 27:791-797

18. Hsiao Y-T, Cheng W-C, Liao W-C et al (2015) Type 1 diabetes and increased risk of subsequent asthma: a nationwide population-based cohort study. Medicine 94:1-6

19. Jensen DM, Damm P, Mølsted-Pedersen L et al (2004) Outcomes in type 1 diabetic pregnancies: a nationwide, population-based study. Diabetes Care 27:2819-2823

20. Parsons LS (2001) Reducing bias in a propensity score matchedpair sample using greedy matching techniques. Available from www2.sas.com/proceedings/sugi26/p214-26.pdf. Accessed 14 Jan 2014

21. Knorr S, Stochholm K, Vlachovâ Z et al (2015) Multisystem morbidity and mortality in offspring of women with type 1 diabetes (The EPICOM Study): a register-based prospective cohort study. Diabetes Care 38:821-826

22. Jensen DM, Korsholm L, Ovesen P et al (2009) Peri-conceptional $A_{1 c}$ and risk of serious adverse pregnancy outcome in 933 women with type 1 diabetes. Diabetes Care 32:1046-1048

23. Helweg-Larsen K (2011) The Danish Register of Causes of Death Scand J Public Health 39:26-29

24. Schmidt M, Schmidt SAJ, Sandegaard JL et al (2015) The Danish National Patient Registry: a review of content, data quality, and research potential. Clin Epidemiol 7:449-490

25. Mors O, Perto GP, Mortensen PB (2011) The Danish Psychiatric Central Research Register. Scand J Public Health 39:54-57

26. Livingstone SJ, Levin D, Looker HC et al (2015) Estimated life expectancy in a Scottish cohort with type 1 diabetes, 2008-2010. JAMA 313:37-44

27. Shankar A, Klein R, Klein BEK, Moss SE (2007) Association between glycosylated hemoglobin level and cardiovascular and all-cause mortality in type 1 diabetes. Am J Epidemiol 166:393-402

28. Lachin JM, Bebu I, Nathan DM et al (2016) Mortality in type 1 diabetes in the DCCT/EDIC versus the general population. Diabetes Care 39:1378-1383

29. Schjoedt KJ, Hansen HP, Tarnow L et al (2008) Long-term prevention of diabetic nephropathy: an audit. Diabetologia 51:956-961

30. Jonasson J, Brismar K, Sparén P (2007) Fertility in women with type 1 diabetes: a population-based cohort study in Sweden. Diabetes Care 30:2271-2276

31. Secher AL, Ringholm L, Andersen HU et al (2013) The effect of real-time continuous glucose monitoring in pregnant women with diabetes: a randomized controlled trial. Diabetes Care 36:18771883 